\title{
Dampak Latihan Push-up Bola Bergulir dan Push-up Tubing pada Hasil Peningkatan Daya Tahan Otot Lengan
}

Hendra Rustiawan ${ }^{\text {** }}$, Andang Rohendi ${ }^{\mathrm{b}}$

abUniversitas Galuh, Indonesia

Correspondence: hendra6610111972@gmail.com

Received: 10 Aug Accepted: 27 Apr 2021 Published: 30 Apr 2021

\begin{abstract}
This study aims to find out about: (1) the effect of rolling ball push up exercises on arm to endurance (2) the effect of push up tubing exercises on to arm endurance (3) the difference between rolling ball push up exercises and push up tubing on power hold arm muscles. This research was a quasi-experimental design studied and usesd quantitative descriptive. The population used was regular students who took physical conditioning development. Totaling 70 experimental group students consisting of 35 rolling ball push-up students, and 35 push-tubing group students. The research sampling technique used subject matched ordinal pairing. The research instrument used was a 1 minute push up. The process of analyzing statistical data uses paired sample t-tests and independent sample t-tests. The results of the study proved that (1) rolling ball push up exercises significantly influenced the increased in endurance of the arm muscles by $0.93 \%$, (2) push up tubing exercises significantly influenced the increased in endurance of the arm muscles by $0.31 \%$. (3) there was no significant difference between rolling ball push up and push up tubing exercised on increased endurance of arm muscles.
\end{abstract}

Keywords: endurance of arm muscles; push up tubing; rolling ball push up.

\begin{abstract}
Abstrak
Tujuan dari penelitian ini untuk mengukur: (1) dampak latihan push up bola bergulir terhadap daya tahan otot lengan (2) dampak latihan push up tubing terhadap daya tahan otot lengan (3) perbedaan antara latihan push up bola bergulir dan push up tubing terhadap daya tahan otot lengan. Penelitian ini merupakan penelitian quasiexperimental designs dan menggunakan deskriptif kuantitatif. Populasi yang digunakan adalah mahasiswa reguler yang mengikuti mata kuliah pembinaan kondisi fisik yang berjumlah 70 mahasiswa putra yang berusia antara 20-22 tahun serta sebelumnya sudah mengisi consent form. Dibagi menjadi kelompok eksperimen yang terdiri dari 35 mahasiswa putra kelompok push up bola bergulir, dan 35 mahasiswa putra kelompok push up tubing. Usianya antara 20-21 tahun. Teknik pengambilan sampel penelitian menggunakan subject matched ordinal pairing. Instrumen penelitian yang digunakan adalah push up selama 1 menit. Proses pengolahan data statistika untuk hipotesisnya yaitu paired sample t-test dan independent sample t-test. Penelitian ini membuktikan bahwa (1) latihan push up bola bergulir berpengaruh secara signifikan pada hasil peningkatan daya tahan otot lengan sebesar $0.93 \%$, (2) latihan push up tubing berpengaruh secara signifikan pada hasil peningkatan daya tahan otot lengan sebesar $0.31 \%$. (3) tidak adanya perbedaan secara berarti antara latihan push up bola bergulir dan push up tubing terhadap peningkatan daya tahan otot lengan.
\end{abstract}

Kata kunci: .push up bola bergulir; push up tubing; daya tahan otot. 


\section{Pendahuluan}

Kondisi fisik yang baik merupakan dambaan semua manusia, tidak terkecuali pada mahasiswa prodi Pendidikan Jasmani Universitas Galuh Ciamis yang wajib dimiliki karena untuk mendukung perkuliahan praktek olahraga. Kondisi fisik sangat dibutuhkan oleh setiap cabang olahraga dengan tujuan untuk meningkatkan performa atlet sehingga diharapkan prestasi dapat diraih secara optimal (Meliala, 2018) Pendapat lain mengatakan bahwa memiliki kondisi fisik yang baik adalah sesuatu hal yang utama dikarenakan para atlet mampu menyelesaikan program latihan yang diberikan oleh pelatihnya (Wibowo, Kusnanik, \& Wiriawan, 2019).

Unsur-unsur kondisi fisik yang diungkap pada penelitian ini yaitu daya tahan (endurance). Hal ini tidak bisa dipungkiri bahwa memiliki daya tahan harus mengikuti program latihan yang sesuai dengan aturan main dari prinsip latihan daya tahan itu sendiri (Dwisetyo, Hartati, Giartama, \& Aryanti, 2019). Daya tahan atau endurance adalah kesanggupan daya pada tubuh ketika bergerak seperti latihan dengan menggunakan waktu yang tidak sebentar dengan intensitas yang sedang (moderat) tanpa mengalami kelelahan yang cukup berat (Rustiawan, 2020).

Komponen kondisi fisik daya tahan terdiri dari daya tahan kardiovaskular dan daya tahan otot. Penulis membatasi hanya bagian otot lengan saja dan tertuju pada komponen kondisi fisik daya tahan (endurance). Penelitian terdahulu mengatakan bahwa daya tahan otot lengan merupakan salah satu yang terpenting karena pendukung berkelanjutan terhadap tugas berikutnya terutama untuk mendukung teknik gerak dalam suatu cabang olahraga yang cenderung memiliki durasi permainan yang lama dan merupakan salah satu anggota tubuh bagian atas untuk bergerak dan untuk meningkatkan daya tahan otot lokal yang ditujukan pada bagian lengan dibutuhkan program latihan daya tahan yang terfokus pada bagian lengan (Surahman, Kanca, \& Tisna, 2018). Ada juga yang berpendapat bahwa kemampuan otot lengan sangat dibutuhkan terutama untuk mempertahankan performa pergerakan lengan yang dilakukan ketika harus dilakukan secara berulang-ulang dalam waktu yang lama terutama saat bertanding seperti dalam pencak silat (Suryawan et al., 2019). Bahkan penelitian tentang atlet yang mengalami epikondilitis lateral yang diakibatkan karena lemahnya kekuatan dan daya tahan otot lengan sehingga tendon otot menjadi rusak atau peradangan (Mehmetoğlu, Ergin, \& Bakırhan, 2019). Pendapat yang sama bahwa lengan termasuk dari anggota gerak bagian atas yang terdiri dari lengan bagian atas dan lengan bagian bawah, panjang lengan terdiri dari panjang lengan atas mulai dari bahu sampai jari tengah (Saputra, Kusuma, \& Festiawan, 2020). Hal tersebut berhubungan dengan penelitian ini karena partisipan yang dijadikan penelitian merupakan mahasiswa aktif yang masih banyak mata kuliah praktek sehingga dengan memiliki daya tahan otot yang baik dan diharapkan para mahasiswa mampu mengikuti mata kuliah praktek dengan baik dan maksimal.

Beberapa penjelasan tentang pengertian daya tahan otot dari penelitian terdahulu antara lain daya tahan otot adalah kapasitas tubuh atau otot ketika melakukan suatu olahraga atau latihan dengan berulangulang(Awang, Pattiserlihun, \& Wibowo, 2017). Daya tahan otot merupakan aktivitas yang dilakukan serta berkelanjutan serta membutuhkan tempo yang tidak sebentar namun tidak menimbulkan kecapaian atau kelelahan yang berat (Prakoso \& Sugiyanto, 2017). Daya kontraksi otot dengan secara terus menerus serta menggunakan beban tertentu dalam waktu yang lama (Yachsie, 2019).

Beberapa penelitian tentang daya tahan otot lengan menerapkan variabel bebas push-up seperti pada penelitian yang menggunakan tiga variabel yaitu push yang biasa dilakukan(tradisional push up), pliometrik push up, dan incline push up, sedangkan variabel terikatnya adalah strength, daya ledak otot, dan muscle endurance. Hasilnya ketiga variabel bebas tersebut berpengaruh secara signifikan terhadap power, strength (kekuatan), dan muscle endurance. (Cahyono, Wiriawan, \& Setijono, 2018). Selanjutnya adalah latihan push up terhadap daya tahan dan kekuatan otot lengan dan gelang bahu. Hasilnya menunjukan bahwa latihan push up tidak berpengaruh lebih besar pada daya tahan dan kekuatan otot lengan serta 
gelang bahu (Zuhdi, Slamet, \& Juita, 2018). Masih dari penelitian push up yang terdahulu untuk peningkatan kekuatan serta daya tahan otot, jenis latihannya adalah push up normal dengan pliometrik push up dan instrument test yang digunakan adalah 1 menit push up. Hasilnya adalah pliometrik push up lebih baik pada kekuatan dan daya tahan otot dibandingkan push up normal (Hassan, 2018). Selanjutnya adalah penelitian push up dan bench press terhadap kecepatan pukulan pada pencak silat. Instrument test yang digunakan adalah stratified random sampling. Hasilnya adalah latihan push up dan bench press berpengaruh secara signifikan terhadap kecepatan pukulan pada pencak silat serta adanya perbedaan antara latihan push up dengan latihan bench press terhadap kecepatan pukulan pada pencak silat (Hidayat, Kadir, \& Duhe, 2019)..

Berdasarkan penelitian terdahulu terlihat bahwa beragam variasi seperti gerakan yang mengerahkan daya ledak otot yang biasa di sebut pliometrik push up, serta gerakan push-up menggunakan alat bantu sehingga push up-nya tidak rata, cenderung tubuh bagian atas lebih tinggi dibandingkan dengan tubuh bagian bawah yang disebut incline push up lebih signifikan dibandingkan dengan push-up biasa atau normal, atau istilah lain yaitu push up tradisional. Hal ini memperlihatkan bahwa variasi push up dapat mengembangkan daya tahan otot lengan. Maka dari itu penelitian ini pun pada dua variabel bebas push up yaitu push up bola bergulir dan push up tubing yang selama ini belum ditemukan adanya penelitian yang sejenis pada dua variabel tersebut. Push up bola bergulir adalah untuk memonitor pengembangan latihan kekuatan dan daya tahan otot lengan dengan cara lima partisipan dalam keadaan posisi push up kemudian luruskan ke dua tangan secara vertical sambil mengangkat badan dan sesegera mungkin bola digelindingkan di bawah ke lima partisipan (Lasinem \& Sabarini, 2010). Variabel penelitian yang pertama adalah push-up bola bergulir, dimana bola adalah sebagai alat bantu dalam melakukan latihan push-up. Agar tidak memerlukan waktu yang cukup banyak latihan push-up bola bergulir ini dilakukan secara berkelompok sehingga para siswa menyukai dan menyenangi gerakan push-up ini karena mengandung unsur bermain.
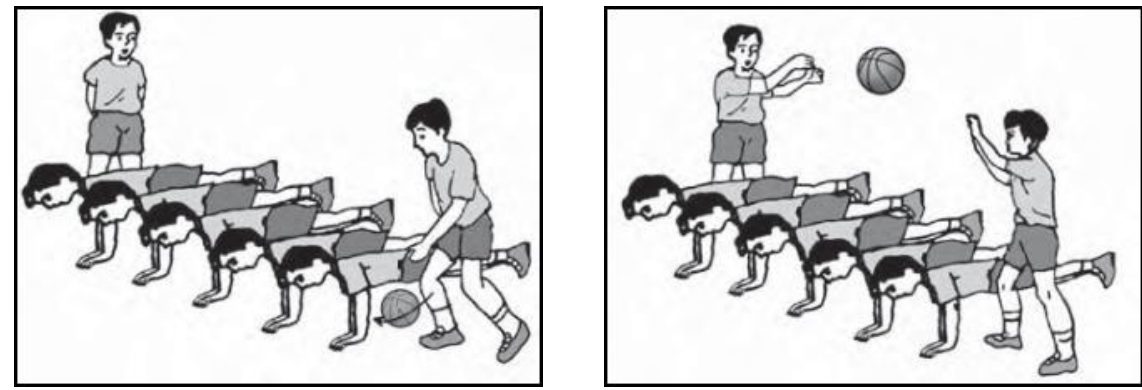

\section{Gambar 1. Latihan Push up Bola Bergulir (Lasinem \& Sabarini, 2010).}

Push up tubing adalah latihan untuk melatih daya tahan otot lengan, bagian ke dua telapak tangan memegang ujung tubing yang sudah dilingkarkan pada tubuh bagian punggung belakang sehingga ketika melakukan push up ada beban atau penahan saat siku dibengkokkan (Maran \& Thomson, 2005). Tubing pada penelitian ini adalah karet yang memiliki pegangan dalam tiap ujungnya dan setiap karet memiliki warna yang memiliki tingkat resistensinya dan berat yang berbeda beda (Aziz, 2019). Warna yang digunakan pada penelitian ini adalah warna hijau muda yang memiliki berat $1.5-2.5 \mathrm{~kg}$. 

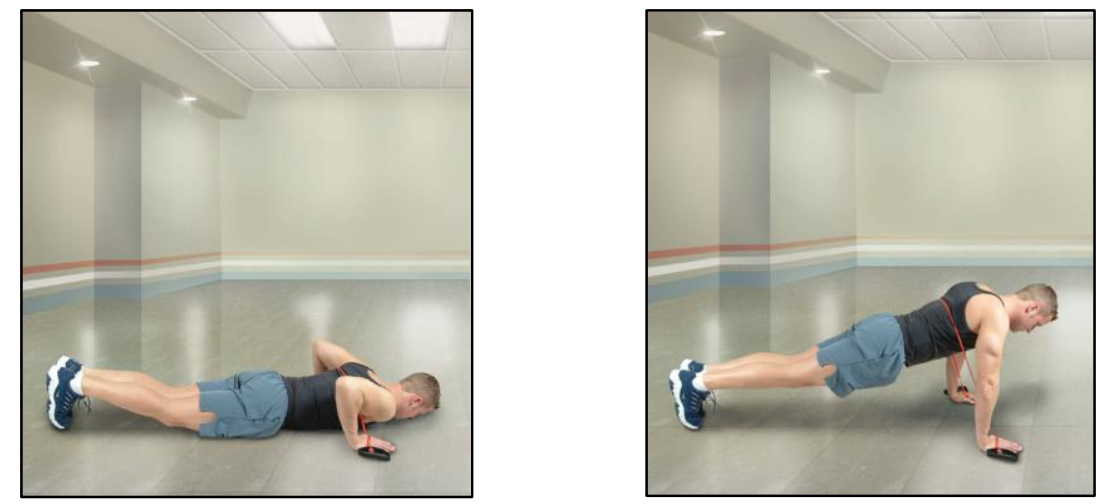

\section{Gambar 2. Latihan Push up Tubing (Maran \& Thomson, 2005)}

Penulis berharap bahwa penelitian ini menjadi salah satu bagian dari prinsip latihan seperti variasi latihan untuk memberikan motivasi bagi pelaku olahraga dalam hal ini adalah atlet, pelatih guru, dan pembina olahraga untuk giat menggerakkan olahraga sebagai aspek psikologi dengan tujuan untuk menghindari kejenuhan (Muskanan, 2015), serta diharapkan juga sebagai pengembangan pengetahuan tentang berbagai jenis push up. Program latihan dibuat secara tersusun dan sistematis yang di dalamnya diterapkan prinsip latihan dan salah satunya adalah variasi latihan (Mubarrok \& Adi, 2017). Penelitian ini diharapkan sebagai kebaruan ilmu pengetahuan dalam mengembangkan jenis latihan push up yaitu push up bola bergulir dan push up tubing yang belum ditemukan penelitian yang sama baik itu push up tubing dan push up bola bergulir yang mengandung unsur permainan dan dilakukan secara bersamasama sehingga dapat menimbulkan rasa menyenangkan. Hal ini sesuai dengan teori bahwa olahraga yang mengandung unsur permainan dijadikan sebagai salah satu cara dalam menciptakan situasi olahraga yang menyenangkan (Siregar, Budiningsih, \& Novitasari, 2018).

Tujuan dari penelitian ini adalah untuk mengetahui dampak latihan push up bola bergulir dan push up tubing terhadap peningkatan daya tahan otot lengan, serta diharapkan penelitian ini memiliki kontribusi pada dunia olahraga sebagai pengembangan ilmu pengetahuan bidang kondisi fisik daya tahan otot lengan.

\section{Metode Penelitian}

Penelitian ini menerapkan metode quasi-experimental designs dan two group pretest-posttest design sebagai desain penelitiannya. Desain penelitian yang digunakan adalah two group pretest-posttest design. Jenis penelitian yaitu deskriptif kuantitatif. Penelitian ini mencakup tes awal, pelatihan atau perlakuan, dan tes akhir (Wicaksono \& Putri, 2020). Populasi penelitian yang digunakan adalah mahasiswa reguler yang mengikuti mata kuliah Pembinaan Kondisi fisik yang berjumlah 79 mahasiswa putra yang berusia antara 20-22 tahun dan memiliki berat badan antara 70-75 kg. Namun sebelumnya seluruh mahasiswa diminta untuk mengisi consent form/informed consent yaitu kesediaan partisipan untuk dijadikan subjek penelitian termasuk riwayat pernah atau tidak mengalami cedera baik pada otot, tulang dan sendi. Teknik pengambilan sampel yang digunakan yaitu purposive sampling sehingga jumlah sampel penelitian yang digunakan adalah 70, hal ini karena berdasarkan tes awal push-up agar seluruh sampel penelitian memiliki kemampuan yang seimbang. Langkah selanjutnya adalah pembagian kelompok penelitian menggunakan subject matched ordinal pairing dengan tujuan agar pembagian kelompok penelitian memiliki kemampuan yang seimbang. Tahapan pelaksanaan terdiri dari partisipan diberikan tes awal daya tahan otot lengan yaitu push up, kemudian hasil tes awal push up tersebut di susun mulai dari yang terbesar sampai yang terkecil kemudian dibagi dua kelompok menggunakan rumus AB BA sehingga memiliki dua kelompok yang kemampuannya sama (Hardinata \& Hidayah, 2015). 
Teknik pengumpulan data dalam penelitian ini dari tes push-up yang pertama adalah penjelasan tes secara terperinci agar saat melakukan tes push up tidak terdapat kesalahan. Kemudian penelitian dimulai dengan adanya pendahuluan yang terdiri dari peregangan dan pemanasan. Sarana dan prasarana yang harus disiapkan terdiri dari ruangan olahraga, bisa juga kelas kosong, stopwatch, dan alat tulis, pembantu pelaksanaan tes berjumlah dua orang yang bertugas untuk menghitung jumlah push up yang diperoleh dan sebagai pengatur waktu.

Langkah-langkah tes push-up:

a. Posisi subjek tidur telungkup dan ke dua lengan ditekukkan sehingga bagian perut dan dada menempel pada lantai.

b. Setelah mendengar aba-aba "Ya" dengan segera ke dua lengan diluruskan sehingga tubuh terangkat kemudian bengkokkan kembali ke dua lengan pada siku sehingga bagian perut dan dada dekat dengan lantai namun tidak menempel pada lantai.

c. Lakukan gerakan push up tersebut sebanyak mungkin selama satu menit.

d. Pengawasan tes push up ini harus dilakukan agar subjek melakukan dengan benar dan jangan sampai subjek meluruskan ke dua lengan namun tidak maksimal atau tidak sesuai dengan petunjuk pelaksanaan push up yang sebelumnya sudah dijelaskan bersamaan dengan peragaan tes push up yang benar.

Catatlah jumlah pengulangan tes push-up sebagai patokan untuk tes awal atau pretest dan setelah mendapatkan perlakuan/pelatihan selama 1.5 bulan kemudian tes lagi sampel penelitian sebagai tes akhir atau posttest. Perencanaan program latihan akan diberikan pada dua kelompok penelitian. Kelompok A adalah push up bola bergulir dan kelompok B adalah push up tubing. Program latihan merujuk pada prinsip-prinsip latihan (Bompa \& Buzzichelli, 2015) yang akan dijelaskan berikutnya setelah tahapan pelaksanaan ke dua kelompok penelitian di bawah ini.

Tahapan latihan push up bola bergulir menurut (Lasinem \& Sabarini, 2010) adalah sebagai berikut :

a. Kelompok push up bola bergulir berjumlah 35 orang dan terdiri dari 7 group dan dalam satu group berjumlah 5 orang.

b. Group pertama melakukan push up bola bergulir dibantu dengan orang dari kelompok kedua yang bertugas sebagai pelempar bola dan penangkap bola sekaligus menggulirkan bola ke bawah.

c. 5 orang pada kelompok pertama berbaris sejajar pada posisi telungkup atau posisi akan melakukan push up secara bersama-sama di lantai.

d. Peluit dibunyikan, dan ke lima orang tersebut melakukan push up secara bersama-sama dan ketika itu dengan segera bola digelindingkan pada lantai tepatnya di sekitar bawah perut.

e. Tiupan peluit kedua kelima orang menurunkan badan dengan membengkokkan ke dua siku tangan sehingga dada dan perut nempel pada lantai. Satu orang yang bertugas menangkap bola kemudian melemparkan bola kepada orang yang bertugas menggulirkan bola ke atas kelompok yang melakukan push up.

f. Latihan ini dilakukan 3 kali dalam seminggu.

Tahapan latihan push up tubing menurut (Speirs, 2010) adalah sebagai berikut :

a. Posisi badan telungkup atau posisi akan melakukan push up.

b. Alat bantu tubing pada bagian ujungnya dipegang/ditahan pada ke dua telapak tangan yang sudah dilingkarkan pada bagian punggung.

c. Peluit dibunyikan lengan kanan dan lengan kiri dibengkokkan pada bagian siku sampai perut dan dada hampir menempel pada lantai.

d. Berikutnya lengan kanan dan lengan kiri diluruskan kembali pada sikap awal.

e. Lakukan push up tubing ini berulang-ulang sesuai program daya tahan.

f. Latihan ini dilakukan 3 kali dalam seminggu. 
Tahapan program latihan yang dilaksanakan pada kelompok push up bola bergulir dan kelompok push up tubing adalah sebagai berikut :

a. Pertemuan latihan: 1.5 bulan (15 kali pertemuan).

b. Banyaknya set : Minggu ke-1 sebanyak 3 set, minggu ke-2 dan ke-6 sebanyak 4 set.

c. Repetisi : Dilakukan selama satu menit.

d. Istirahat : :1-3 menit.

Setelah melakukan perlakuan selama 1.5 bulan langkah selanjutnya adalah pengumpulan data diambil berdasarkan data tes awal dan tes akhir menggunakan tes push up selama 1 menit. Ke dua data tersebut di analisis menggunakan statistika berdasarkan hipotesis yang diajukan yaitu uji paired sample $t$-test dan uji independent sample t-test.

\section{Hasil}

Langkah pertama pada hasil pengolahan data adalah deskripsi data kelompok push up bola bergulir dan push up tubing dengan tujuan untuk mengetahui hasil pembagian ke dua kelompok penelitian memiliki kemampuan yang seimbang terutama pada deskripsi data tes awal yang terdiri dari mean atau rata-rata, data atau skor yang paling rendah dan skor yang paling tinggi pada tabel 1.

Tabel 1. Deskripsi Tes Awal Push up

\begin{tabular}{lcccccc}
\hline \multicolumn{1}{c}{ Kelompok } & Jumlah & Rata-rata & $\begin{array}{c}\text { Std. } \\
\text { Deviation }\end{array}$ & Variance & $\begin{array}{c}\text { Skor } \\
\text { terendah }\end{array}$ & $\begin{array}{c}\text { Skor } \\
\text { tertinggi }\end{array}$ \\
\hline Push up bola bergulir & 35 & 25.74 & 3.09 & 9.55 & 19 & 31 \\
Push up tubing & 35 & 25.20 & 3.62 & 13.11 & 18 & 31 \\
\hline
\end{tabular}

Berdasarkan hasil deskripsi data tes awal yang terdiri dari rata-rata kelompok push up bola bergulir adalah 25.74, standar deviasi adalah 3.09, variance adalah 9.55, skor paling rendah yaitu 19 dan skor paling tinggi yaitu 31. Pada kelompok push up tubing rata-ratanya adalah 25.20, standar deviasi adalah 3.62, variance adalah 13.11, skor paling rendah yaitu 18 dan skor paling tinggi yaitu 31. Selanjutnya hasil deskripsi data tes akhir pada tabel 2.

Tabel 2. Deskripsi Tes Akhir Push up

\begin{tabular}{lcccccc}
\hline \multicolumn{1}{c}{ Kelompok } & Jumlah & Rata-rata & $\begin{array}{c}\text { Std. } \\
\text { Deviation }\end{array}$ & Variance & $\begin{array}{c}\text { Skor } \\
\text { terendah }\end{array}$ & $\begin{array}{c}\text { Skor } \\
\text { tertinggi }\end{array}$ \\
\hline Push up bola bergulir & 35 & 28.05 & 3.46 & 11.99 & 20 & 34 \\
Push up tubing & 35 & 26.28 & 3.49 & 12.21 & 20 & 32 \\
\hline
\end{tabular}

Berdasarkan hasil deskripsi data tes akhir yang terdiri dari rata-rata kelompok push up bola bergulir adalah 28.05, standar deviasi adalah 3.46, variance adalah 11.99, skor paling rendah yaitu 20 dan skor paling tinggi yaitu 34. Pada kelompok push up tubing rata-ratanya adalah 26.28, standar deviasi adalah 3.49, variance adalah 12.21, skor paling rendah yaitu 20 dan skor paling tinggi yaitu 32.

Langkah selanjutnya adalah uji normalitas dengan tujuan agar diketahui sampel penelitian atau partisipan memiliki kemampuan tes push up-nya masuk pada kategori normal atau tidak sehingga penulis mencantumkan hasil uji normalitas pada tabel 3 di bawah ini. 
Tabel 3. Hasil Uji Normalitas Data Tes Awal Push up

\begin{tabular}{clrll}
\hline \multirow{2}{*}{ Tes Push up } & \multirow{2}{*}{ Kelompok } & \multicolumn{3}{c}{ Shapiro-Wilk } \\
\cline { 3 - 5 } & & Statistik & df & Sig \\
\hline \multirow{2}{*}{ Tes awal } & Push up bola bergulir & 0.971 & 35 & 0.485 \\
& Push up tubing & 0.947 & 35 & 0.089 \\
\hline
\end{tabular}

Berdasarkan kriteria keputusan dan uji kenormalan dari tabel 3 diketahui bahwa data dari tes push up untuk tes awal pada kelompok push up bola bergulir memiliki data 0.485 lebih besar dari 0.05 sehingga kelompok push up bergulir berdistribusi normal. Pada kelompok push up tubing hasil uji normalitas pada tes awal memiliki data 0.089 lebih besar dari 0.05. Artinya bahwa kelompok push up tubing berdistribusi normal.

Tabel 4. Hasil Uji Normalitas Data Tes Akhir Push up

\begin{tabular}{|c|c|c|c|c|}
\hline \multirow{2}{*}{ Tes Push up } & \multirow{2}{*}{ Kelompok } & \multicolumn{3}{|c|}{ Shapiro-Wilk } \\
\hline & & Statistik & df & Sig \\
\hline \multirow{2}{*}{ Tes akhir } & Push up bola bergulir & 0.979 & 35 & 0.722 \\
\hline & Push up tubing & 0.939 & 35 & 0.063 \\
\hline
\end{tabular}

Berdasarkan kriteria keputusan dan uji kenormalan dari tabel 4 diketahui bahwa data dari tes push up untuk tes akhir pada kelompok push up bola bergulir memiliki data 0.722 lebih besar dari 0.05 sehingga kelompok push up bergulir berdistribusi normal. Pada kelompok push up tubing hasil uji normalitas pada tes akhir memiliki data 0.063 lebih besar dari 0.05. Artinya bahwa kelompok push up tubing berdistribusi normal.

Langkah berikutnya adalah uji homogenitas dengan tujuan untuk mengetahui data dari kelompok push up bola bergulir dan kelompok push up tubing termasuk pada data homogen atau tidak. Hal ini dapat dilihat dari rata-rata (mean) dan nilai tengah (median) pada tabel 5 di bawah ini.

\section{Tabel 5. Hasil Uji Homogenitas Tes Awal dan Tes Akhir Push up Kelompok Push up Bola Bergulir dan Kelompok Push up Tubing}

\begin{tabular}{ccccc}
\hline Tes Push up & Rata-rata & Nilai Tengah & Hasil & Keterangan \\
\hline Tes awal & 0.170 & 0.247 & $>0.05$ & Homogen \\
Tes akhir & 0.653 & 0.762 & $>0.05$ & Homogen \\
\hline
\end{tabular}

Berdasarkan tabel 5 hasil uji homogenitas memperlihatkan bahwa data tes awal dan tes akhir push up dari kelompok push up bola bergulir dan kelompok push up tubing lebih besar dari 0.05. Artinya bahwa data tes awal dan tes akhir memiliki data yang homogen.

Selanjutnya adalah uji hipotesis pertama yang akan dijabarkan dalam bentuk tabel hasil dari uji $\mathrm{T}$ berpasangan atau paired sample t-test yang dipakai untuk membandingkan selisih rata-rata (mean) dari dua data yang berkaitan atau berpasangan antara tes awal dengan tes akhir yang dites dari waktu yang berbeda yaitu belum diberikan perlakuan dan sudah diberikan perlakuan kelompok push up bola bergulir dan push up tubing pada tabel 6. 
Tabel 6. Data Uji T Berpasangan

\begin{tabular}{ccccccccc}
\hline \multirow{2}{*}{ Kelompok } & \multirow{2}{*}{ Rata-rata } & \multirow{2}{*}{ Std. Deviation } & \multicolumn{3}{c}{$\begin{array}{c}\text { Perbedaan tingkat } \\
\text { Kepercayaan 95\% }\end{array}$} & \multirow{2}{*}{ t-hitung } & dk & Signifikansi \\
\cline { 4 - 6 } & & & \multicolumn{2}{c}{ Lower } & Upper & & & \\
\hline $\begin{array}{c}\text { Push up bola } \\
\text { bergulir }\end{array}$ & 2,31 & 0,90 & 2,62 & 2,00 & 15,212 & 34 & 0,000 \\
Push up tubing & 1,08 & 0,28 & 1.18 & 0.99 & 22.61 & 34 & 0.000 \\
\hline
\end{tabular}

Nilai signifikansi 0.000 kemudian displit 2 hasilnya 0. Berdasarkan data tabel 3 bahwa tes push up hasilnya yaitu $0.000<0.025$ untuk kelompok push up bola bergulir dan $0.000<0.025$ untuk kelompok push up tubing. Kesimpulan berdasarkan data tabel 3 Ho ditolak, kesimpulannya yaitu kelompok latihan push up bola bergulir dan push up tubing memiliki pengaruh yang lebih besar (signifikansi) pada daya tahan otot lengan.

Langkah selanjutnya yaitu uji hipotesis yang kedua yaitu uji beda dengan tujuan untuk melihat adanya perbedaan di antara dua kelompok yaitu kelompok latihan push up bola bergulir dan push up tubing pada tabel 7.

Tabel 7. Uji Beda Kelompok Push up Bergulir dan Push up Tubing

\begin{tabular}{|c|c|c|c|c|c|}
\hline \multirow[t]{2}{*}{ Tes Push up } & \multicolumn{2}{|c|}{ Uji Levene } & \multicolumn{2}{|c|}{$\begin{array}{c}\text { T-Test Kes. Rata- } \\
\text { rata }\end{array}$} & \multirow{2}{*}{$\begin{array}{l}\text { Keterang } \\
\text { an }\end{array}$} \\
\hline & Sig. & $\mathbf{t}$ & dk & Sig. 2 tailed & \\
\hline Asumsi varians sama & 0.65 & 2.130 & 68 & 0.037 & Sig. \\
\hline $\begin{array}{l}\text { Asumsi varians tidak } \\
\text { sama }\end{array}$ & & 2.130 & 67.99 & 0.037 & Sig. \\
\hline
\end{tabular}

Hipotesis yang diuraikan yang terdiri dari Ho = Perbedaannya tidak ada pada rata-rata kelompok push up bola bergulir dan kelompok push up tubing pada hasil peningkatan daya tahan otot lengan, sedangkan pada $\mathrm{Ha}=$ Perbedaannya ada pada rata-rata kelompok push up bola bergulir dan kelompok push up tubing pada hasil peningkatan daya tahan otot lengan. Selanjutnya pengolahan data pada t hitung. Berdasarkan data, hasilnya yaitu 2.130. Selanjutnya berdasarkan t tabel yaitu signifikansi untuk 0.05:2 $=0.025$ derajat kebebasan yaitu jumlah keseluruhan data dari sampel siswa yang terlibat (dk) n-2 yaitu $70-2=68$ dan dilihat pada $\mathrm{t}$ tabel yaitu 1.995 .

Kriteria Pengujian apabila t tabel lebih kecil atau sama dengan dari thitung maka Ho diterima. Namun apabila -t hitung lebih kecil dari t tabel (t hitung lebih besar dari $t$ tabel) maka Ho ditolak. Berdasarkan hasil data penelitian ini bahwa $-2.130<-1.995$ maka Ho ditolak. Kesimpulannya yaitu adanya perbedaan pada rata-rata (mean) dan skor tinggi dan skor rendah pada tes akhir hasil perlakuan pada peningkatan daya tahan otot lengan antara kelompok push up bola bergulir dengan kelompok push up tubing. 


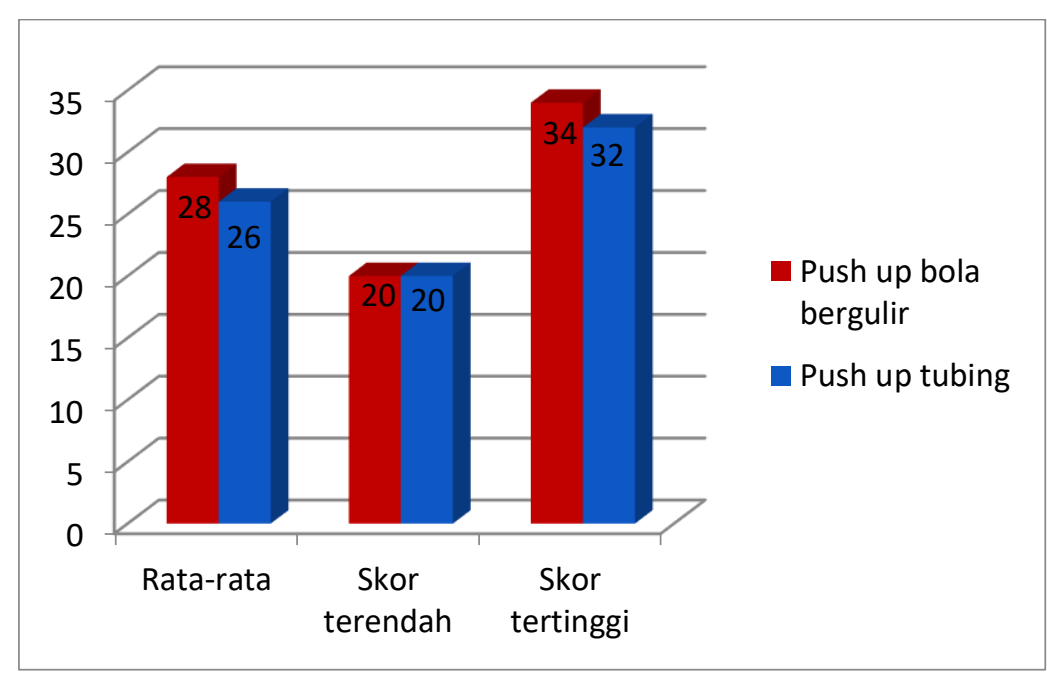

\section{Gambar 3. Perbedaan Hasil Tes Akhir Push up antara Kelompok Push up Bola Bergulir dan Push up Tubing}

Tujuan adanya grafik 1 adalah untuk memudahkan perbedaan hasil tes akhir antara kelompok push up bola bergulir dengan kelompok push up tubing. Penulis berasumsi bahwa data tes akhir merupakan hasil dari perlakuan selama 1.5 bulan dari dua kelompok penelitian sehingga dapat dilihat adanya peningkatan berdasarkan data tes akhir dari dua kelompok penelitian tersebut. Dimulai kelompok push up bola bergulir memiliki rata-rata sebesar 28 sedangkan kelompok push up tubing memiliki rata-rata sebesar 26. Artinya bahwa kelompok push up bola bergulir rata-rata nya lebih besar dibandingkan dengan kelompok push up tubing. Pada bagian skor terendah kelompok push up bola bergulir dan kelompok push up tubing memiliki skor yang sama yaitu 20, dan pada bagian skor tertinggi kelompok push up bola bergulir adalah 34 sedangkan kelompok push up tubing lebih kecil yaitu 32.

\section{Pembahasan}

Berdasarkan deskripsi data hasil tes push up selama satu menit pada tes awal terlihat bahwa dari data rata-rata, skor terendah dan skor tertinggi dapat dikatakan memiliki kemampuan daya tahan otot lengan yang sama sehingga pembagian kelompok penelitian yang terdiri dari kelompok push up bola bergulir dan kelompok push up tubing menggunakan subject matched ordinal pairing. Artinya bahwa adanya keseimbangan pembagian kelompok berdasarkan tingkat kemampuan masing-masing sampel penelitian menggunakan rumus $\mathrm{AB} B \mathrm{BA}$ sesuai dengan pelaksanaan penelitian ini (Hardinata \& Hidayah, 2015) dan bahkan penelitian terdahulu menegaskan bahwa pembagian kelompok dengan cara matched subject ordinal pairing (MSOP) lebih seimbang dan objektif untuk semua penelitian, karena cara ini memiliki kesempatan bagi anggota objek penelitian dapat masuk pada setiap kelompok (Pratama, Hardiono, \& Martinus, 2018).

Berdasarkan hasil penelitian pada kelompok push up bola bergulir mengalami peningkatan daya tahan otot sebesar 3 poin dari skor tertinggi pada tes awal 31 sedangkan skor tertinggi pada tes akhir 34, hal ini memperlihatkan adanya peningkatan sebesar $0.93 \%$. Hal ini memperlihatkan bahwa push up bola bergulir membuktikan adanya peningkatan daya tahan otot lengan, serta adanya jeda waktu beberapa detik ketika meluruskan ke dua lengan karena menunggu bola bergulir di bawah subjek sehingga otototot tubuh lebih terlatih seperti otot lengan, biceps, triceps, bahu, dan otot dada (Irawan \& Sandiyudha, 2018). Ketika push up dalam posisi tangan lurus dalam waktu yang cukup lama dan berbagai variasi push up sangat menguntungkan pada otot lengan dan dada karena adanya kontraksi isometrik dan adanya dampak pada bagian otot perut dibandingkan dengan gerakan push up apabila ke dua lengan lurus dan sesegera mungkin menurunkan atau membengkokkan siku (Calatayud et al., 2014). Push up dengan bola yang digulirkan di bawahnya memiliki tantangan bagi partisipannya sehingga berusaha untuk 
mempertahankan posisi push up dalam keadaan ke dua lengan lurus menunggu bola melewatinya. Hal ini memberikan manfaat bahwa semakin lama dilakukan semakin tubuh tidak akan stabil karena energi terkuras terutama pada bagian otot lengan sebagai pondasi. Hal ini sesuai dengan penelitian yang terdahulu tentang perbedaan push up stabil dengan push up yang tidak stabil (Anderson, Gaetz, Holzmann, \& Twist, 2011). Hal yang sama diungkapkan bahwa ketika mempertahankan posisi dalam keadaan telungkup seperti gerakan push up dapat melibatkan otot perut bahkan mempertahankan dalam waktu yang cukup lama akan menimbulkan berbagai kontraksi otot secara isometrik (Lehman, MacMillan, MacIntyre, Chivers, \& Fluter, 2006). Pada kelompok push up bola bergulir dilakukan secara bersama sama, hal ini memperlihatkan adanya kegembiraan dan menyenangkan. Hal ini berhubungan dengan penelitian yang mengatakan bahwa apabila olahraga atau aktivitas yang dilakukan secara bersama sama dapat menghindari asupan makanan camilan yang tidak perlu karena sudah bersusah payah olahraga bersama demi kesehatan tubuh agar memiliki tubuh yang ideal (Werle, Wansink, \& Payne, 2014). Penelitian terdahulu yang lainnya mengatakan bahwa latihan push up dengan berbagai variasinya mampu meningkatkan kekuatan dan daya tahan otot ketika berkontraksi terutama saat tekanan mendorong tubuh bagian atas seperti otot dada, otot tricep, otot bahu, dan otot perut (Azeem, 2015). Penulis menyimpulkan bahwa penelitian dengan berbagai variasi push up berhubungan dengan penelitian ini yang mana push up bola bergulir dengan push up tubing merupakan salah satu variasi push up. Push up tidak hanya untuk mengembangkan komponen kondisi fisik daya tahan otot pada tubuh bagian atas saja, namun penelitian lain mengungkapkan dapat dijadikan pengembangan pada komponen kondisi fisik yang lain dan salah satunya adalah power terutama untuk pergerakan bagian lengan yang menuntut pengerahan kekuatan dan kecepatan yang disesuaikan dengan kebutuhan cabang olahraganya (Zalleg et al., 2018). Penelitian selanjutnya membandingkan antara push up dengan bench press, terbukti bahwa hasilnya untuk kekuatan bench press lebih meningkat dibandingkan dengan push up, namun kelebihan dari push up seperti mampu menerapkan berbagai komponen kondisi fisik terdiri dari kekuatan, kecepatan, power, dan daya tahan otot. Tidak hanya itu, bahwa push up memiliki variasi yang lebih banyak dibandingkan dengan bench press, bahkan dapat dilakukan segala umur, jenis kelamin, dan dapat dilakukan dimana saja dibandingkan dengan bench press (Kikuchi \& Nakazato, 2017). Hubungan dengan penelitian ini penulis beranggapan bahwa sesuai dengan yang diungkapkan karena latihan push up bola bergulir dengan push up tubing merupakan termasuk pada variasi push up, berbagai komponen dapat diterapkan, serta dapat dilakukan dimana saja. Penelitian lain pun mengatakan bahwa push up dapat meningkatkan kekuatan dan daya tahan otot. Sangat perlu sekali bagi para peneliti untuk memiliki pengetahuan tentang variasi push up agar dapat mengoptimalkan otot mana yang akan dilatih dengan gerakan push up dengan pertimbangan cedera yang dialami (Contreras et al., 2012).

Berdasarkan pada kelompok push up tubing mengalami peningkatan daya tahan otot sebesar 1 poin dari skor tertinggi pada tes awal 31sedangkan skor tertinggi pada tes akhir 32, hal ini memperlihatkan adanya peningkatan sebesar $0.31 \%$. Hal ini memperlihatkan bahwa push up tubing memperlihatkan peningkatan daya tahan otot lengan. Penelitian terdahulu mengatakan bahwa latihan push up dapat ditingkatkan pada daya tahan otot terutama lengan, dada, dan bahu (Contreras et al., 2012). Penelitian terdahulu mengatakan bahwa push up tubing untuk melatih pada bagian otot dada (chest), bahu bagian depan (anterior deltoid/shoulder), dan triceps (Knopf, 2013). Penelitian lain mengatakan bahwa tidak hanya daya tahan otot lengan, namun lebih banyak lagi manfaat latihan push up tubing dengan nama lain yaitu elastic-band resistance exercise antara lain adalah untuk meningkatkan keseimbangan, mobilitas pergerakan tubuh, cara berjalan dengan benar, fleksibilitas otot, dan stabilitas titik berat tubuh saat berdiri pada sebagian orang yang bukan pelaku olahraga terutama para orang tua (Kwak, Kim, \& Lee, 2016). Bahkan push up dijadikan sebagai bagian untuk rehabilitasi bidang kesehatan yang ditujukan untuk anak-anak penderita diplegic yaitu penderita gangguan motorik dan postur sehingga aktivitas geraknya terganggu atau terbatas dimana gerakan push up dijadikan sebagai media penyembuhan pada bagian telapak tangan agar mampu bergerak, jari-jari tangan lebih baik pegangannya atau cengkeraman seperti berpegang pada suatu benda (Hegazy, El-negamy, Kamal, \& Hendawy, 2019). Hal ini mendekati pada latihan push up tubing karena telapak tangan saat melakukan push up tubing menggenggam ujung karet/tubing sehingga jari tangan ikut bekerja atau berkontraksi dari otot jari tangannya. 


\section{Simpulan dan Rekomendasi}

Kesimpulan dari penelitian ini dapat dijelaskan yaitu kelompok latihan push up bola bergulir dengan kelompok push up tubing berpengaruh secara signifikan terhadap daya tahan otot lengan serta ke dua kelompok tersebut tidak ada perbedaan, bahkan dapat dikatakan sama-sama efektif untuk meningkatkan daya tahan otot lengan.

Berdasarkan simpulan yang sudah dijelaskan, bahwa dapat diungkapkan sebagai salah satu rekomendasi bagi para pelatih khususnya pelatih kondisi fisik, praktisi olahraga prestasi maupun pendidikan jasmani, dan peneliti sebagai kelanjutan dalam mengembangkan hasil penelitian ini yang dapat diterapkan sehingga penelitian ini bermanfaat. Berdasarkan hasil penelitian bahwa latihan push up bola bergulir dan push up tubing terdapat pengaruh yang lebih baik pada hasil daya tahan otot lengan dan diharapkan adanya pengembangan ilmu pengetahuan khususnya pada daya tahan otot lengan khususnya bagi peneliti dalam mengembangkan permasalahan yang sesuai dengan jenis permasalahan penelitian yang sama.

\section{Daftar Pustaka:}

Anderson, G. S., Gaetz, M., Holzmann, M., \& Twist, P. (2011). Comparison of EMG activity during stable and unstable push-up protocols. European Journal of Sport Science, O0(00), 1-7. https://doi.org/10.1080/17461391.2011.577240

Awang, J. K., Pattiserlihun, A., \& Wibowo, N. A. (2017). Pengaruh Profesi Pekerjaan Terhadap Kekuatan dan Daya Tahan Otot Tangan di Kecamatan Sidorejo, Salatiga. Prosiding Lontar Physic, 4(4), 249-256.

Azeem, K. (2015). The Push - up. International Journal of Fitness, Health, Physical Education \& Iron Games, 2(1), 1-5.

Aziz, N. (2019). Pengaruh Latihan 8 Minggu Dengan Resistance Band di Periode Khusus Terhadap Power Tungkai Atlet Taekwondo. Universitas Negeri Yogyakarta.

Bompa, T., \& Buzzichelli, C. (2015). Periodization training for sports, 3e. Human kinetics.

Cahyono, F. D., Wiriawan, O., \& Setijono, H. (2018). Pengaruh Latihan Traditional Push Up, Plyometric Push Up, dan Incline Push Up Terhadap Kekuatan Otot Lengan, Power Otot Lengan, dan Daya Tahan Otot Lengan. Jumal SPORTIF: Jurnal Penelitian Pembelajaran, 4(1), 54 72. https://doi.org/10.29407/js_unpgri.v4i1.12004

Calatayud, J., Borreani, S., Colado, J. C., Martin, F., Batalha, N., \& Silva, A. (2014). Muscle activation differences between stable push-ups and push-ups with a unilateral v-shaped suspension system at different heights. Motricidade, 10(4), 85-93. https://doi.org/10.6063/motricidade.10(4).3395

Contreras, B., Schoenfeld, B., Mike, J., Tiryaki-Sonmez, G., Cronin, J., \& Vaino, E. (2012). The biomechanics of the push-up: Implications for resistance training programs. Strength and Conditioning Journal, 34(5), 41-46. https://doi.org/10.1519/SSC.0b013e31826d877b

Dwisetyo, M. R., Hartati, Giartama, \& Aryanti, S. (2019). Pengaruh Interval Training Terhadap Volume Oksigen Maksimal Pada Kegiatan Ekstrakurikuler Futsal. JOSSAE Journal Of Sport Science And Education), 4(1), 21-25. https://doi.org/10.26740/jossae.v4n1.p21-25

Hardinata, A. F., \& Hidayah, T. (2015). Pengaruh Jeda/Interval Pada Latihan Tusukan Terhadap Ketepatan Tusukan Pada Pemain Anggar IKASI Kota Semarang Tahun 2015. Journal of Sport Sciences and Fitness, 4(4), 6-10.

Hassan, S. (2018). The Effects of Push-Up Training on Muscular Strength and Muscular Endurance. International Journal of Academic Research in Business and Social Sciences, 8(11), 660-665. https://doi.org/10.6007/ijarbss/v8-i11/4940 
Hegazy, R. H., El-negamy, E. H., Kamal, H. M., \& Hendawy, A. S. (2019). Effect of push-up exercises on hand grip strength in diplegic children . Biomedical Research, 30(2), 366-370. https://doi.org/https://doi.org/10.35841/biomedicalresearch.30-19-115

Hidayat, S., Kadir, S., \& Duhe, E. D. P. (2019). Pengaruh Latihan Push up dan Latihan Bench press Terhadap Kecepatan Pukulan Pada Pencaksilat. COMPETITOR: Jurnal Pendidikan Kepelatihan Olabraga, 11(2), 94-101.

Irawan, F. A., \& Sandiyudha, T. B. (2018). Pengembangan Alat Bantu Push-Up (Push-Up Counting) Sebagai Alternatif Perangkat Kebugaran Jasmani. Jurnal Media Ilmu Keolahragaan Indonesia, 8(1), 26-30. https://doi.org/10.15294/miki.v8i1.17183

Kikuchi, N., \& Nakazato, K. (2017). Low-load bench press and push-up induce similar muscle hypertrophy and strength gain. Journal of Exercise Science \& Fitness, 15(1), 37-42. https://doi.org/10.1016/j.jesf.2017.06.003

Knopf, K. (2013). Resistance Band Workbook (First; L. Chou, Ed.). United States: Ulysses Press. https://doi.org/10.16309/j.cnki.issn.1007-1776.2003.03.004

Kwak, C. J., Kim, Y. L., \& Lee, S. M. (2016). Effects of elastic-band resistance exercise on balance, mobility and gait function, flexibility and fall efficacy in elderly people. Journal of Physical Therapy Science, 28(11), 3189-3196. https://doi.org/10.1589/jpts.28.3189

Lasinem, \& Sabarini, S. S. (2010). Pendidikan Jasmani, Olahraga, dan Kesehatan. In Journal of Chemical Information and Modeling (Vol. 53). Jakarta: Kementerian Pendidikan Nasional.

Lehman, G. J., MacMillan, B., MacIntyre, I., Chivers, M., \& Fluter, M. (2006). Shoulder muscle EMG activity during push up variations on and off a Swiss ball. Dynamic Medicine, 5(7), 1-7. https://doi.org/10.1186/1476-5918-5-7

Maran, \& Thomson. (2005). Weight Training (first). U.S. and Canada by Thomson Course Technology: maranGraphics Inc. https://doi.org/10.16309/j.cnki.issn.1007-1776.2003.03.004

Mehmetoğlu, G., Ergin, G., \& Bakırhan, S. (2019). The Effects of Muscle Strength and Muscle Endurance on Upper Extremity Functions of Lateral Epicondylitis Patients The Effects of Muscle Strength and Muscle Endurance on Upper Extremity Functions of Lateral Epicondylitis Patients. Journal of Basic and Clinical Health Sciences, 3(1), 16-21. https://doi.org/10.30621/jbachs.2019.503

Meliala, E. K. br. (2018). Analisis Kondisi Fisik Atlet Putra Floorball Universitas Negeri Surabaya. JOSSAE: Journal of Sport Science and Education, 3(2), 8193. https://doi.org/10.26740/jossae.v3n2.p81-93

Mubarrok, M., \& Adi, S. (2017). Pengaruh Variasi Latihan Squat Terhadap Peningkatan Power Otot Tungkai pada Pemain Bolavoli Putri. Indonesia Performance Journal, 1(2), 125-129.

Muskanan, K. (2015). Analisis Motivasi Berprestasi Atlet Pusat Pendidikan dan Latihan Olahraga Pelajar (PPLP) Provinsi Nusa Tenggara Timur. JKAP (Jurnal Kebijakan Dan Administrasi Publik), 19(2), 105-113. https://doi.org/10.22146/jkap.7608

Prakoso, G. P. W., \& Sugiyanto, F. (2017). Pengaruh metode latihan dan daya tahan otot tungkai terhadap hasil peningkatan kapasitas VO2Max pemain bola basket. Jurnal Keolabragaan, 5(2), 151 161. https://doi.org/10.21831/jk.v5i2.10177

Pratama, R., Hardiono, B., \& Martinus. (2018). Perbandingan Hasil Latihan Kelinchan di Tiga Media Tempat Pada Pemain Bolabasket Binadarma. Jurnal Sains Keolahragaan \& Kesehatan, 3(1), 483-490.

Rustiawan, H. (2020). Pengaruh Latihan Interval Training dengan Running Circuit Terhadap PeningkatanVo2 Max. Jurnal Wahana Pendidikan, 7(1), 15-28. 
Saputra, S. H., Kusuma, I. J., \& Festiawan, R. (2020). Hubungan Tinggi Badan, Panjang Lengan Dan Daya Tahan Otot Lengan Dengan Keterampilan Bermain Bulutangkis. Jurnal Pendidikan Olahraga, 9(1), 93-108. https://doi.org/10.31571/jpo.v9i1.1744

Siregar, N. M., Budiningsih, M., \& Novitasari, E. F. (2018). Model Latihan Kelentukan Berbasis Permainan Untuk Anak Usia 6 Sampai 12 Tahun. Prosiding Seminar Dan Lokakarya Fakultas Ilmu Keolahragaan Universitas Negeri Jakarta, 3(1), 75-88.

Speirs, S. (2010). 7 Weeks to 100 Push-ups. In L. Chou (Ed.), Published in the United States by UlySSeS PreSS (Vol. 369). Canada: UlySSeS PreSS.

Surahman, H. B., Kanca, I. N., \& Tisna, G. D. (2018). Pengaruh Pelatihan Bermain Bulutangkis Overhead Clear Drill Terhadap Kekuatan Dan Daya Tahan Otot Lengan. Jurnal Ilmu Keolahragaan Undiksha, 6(3), 20-27. https://doi.org/10.23887/jiku.v6i3.2650

Suryawan, I., Pangkahila, J. A., Satriyasa, B. K., Adiputra, L. H., Griadi, I. A., \& Wirawan, I. (2019). Pelatihan Daya Tahan Otot berbeban $1 / 2 \mathrm{~kg} 20$ repetisi 3 set lebih meningkatkan frekuensi pukulan pendeta tangan kiri dan kanan dari pada 15 repetisi 4 set pada anggota pencak Silat Perisai Diri Ranting Sesetan. Jurnal Pendidikan Kesehatan Rekreasi, 5(2), 26-33. https://doi.org/10.5281/zenodo.3338702

Werle, C. O. C., Wansink, B., \& Payne, C. R. (2014). Is it fun or exercise ? The framing of physical activity biases subsequent snacking. Mark Lett, 26(4), 1-13. https://doi.org/10.1007/s11002014-9301-6

Wibowo, S. P. K., Kusnanik, N. W., \& Wiriawan, O. (2019). Pengaruh High Intensity Interval Training ( HIIT ) terhadap Daya Tahan Kardiovaskuler, Kecepatan, dan Kelincahan pada Usia 13-15 Tahun. JOSSAE Journal Of Sport Science And Education), 4(2), 79-84. https://doi.org/http://dx.doi.org/10.26740/jossae.v4n2.p79-84

Wicaksono, T., \& Putri, W. S. K. (2020). Pengaruh Latihan Burpee dan Box Jump Terhadap Daya Ledak Otot Tungkai dan Kecepatan Renang. JOSS AE (Journal of Sport Science and Education), 5(1), $39-47$.

Yachsie, B. T. P. W. B. (2019). Pengaruh Latihan Dumbell-Thera Band Terhadap Daya Tahan Otot Lengan Dan Akurasi Memanah Pada Atlet Panahan. Medikora, 18(2), 79-85. https://doi.org/10.21831/medikora.v18i2.29200

Zalleg, D., Ben Dhahbi, A., Dhahbi, W., Sellami, M., Padulo, J., Souaifi, M., ... Chamari, K. (2018). Explosive Push-ups: From Popular Simple Exercises to Valid Tests for Upper-Body Power. Journal of Strength and Conditioning Research, 00(00), 1-10. https://doi.org/10.1519/JSC.0000000000002774

Zuhdi, M., Slamet, \& Juita, A. (2018). Pengaruh Latihan Push Up Terhadap Daya Tahan Kekuatan Otot Lengan Dan Bahu Atlet Anggar Putra Junior Siak Fencing Club. Jurnal Online Mahasiswa, 5(1), 1-10. 